\title{
Suppression of Performance Curve Instability of an Axial-Flow Pump by Using a Double-Inlet-Nozzle
}

\author{
P. Pérez Flores, G. Kosyna, and D. Wulff \\ Pfleiderer-Institut, TU-Braunschweig, Langer Kamp 6, 38106 Braunschweig, Germany \\ Correspondence should be addressed to P. Pérez Flores, perez@pfi.tu-bs.de
}

Received 10 April 2008; Accepted 16 June 2008

Recommended by Seung Jin Song

It has been shown that the sudden decrease of pump head in an axial flow pump caused by stall can be overcome by means of casing treatment. Flat axial grooves in front of the impeller break the swirl of the near-casing backflow. The disadvantage of this method is strong cavitation at the inlet of the grooves for flow rates below the stall point. In this paper another improved method to stabilize the performance curve will be presented, using a double-inlet-nozzle. At the onset of stall the initial near-casing backflow with its high swirl is lead off into the gap between both nozzles. At design conditions this double-inlet-nozzle is working as an injector, supporting the near-casing-inflow. The function of the double-inlet-nozzle is demonstrated by PIV-measurements.

Copyright (c) 2008 P. Pérez Flores et al. This is an open access article distributed under the Creative Commons Attribution License, which permits unrestricted use, distribution, and reproduction in any medium, provided the original work is properly cited.

\section{INTRODUCTION}

The operating range of axial-flow pumps is often limited by the onset of stall. If the flow rate is reduced approximately below $70 \%$ of the design flow rate the characteristics will become unstable with a sudden drop of pump head. Already before stall, the $\mathrm{NPSH}_{3}$-values are rising and cavitation cause severe vibration. When stall inception is caused by tip- or wall-stall, it is possible to overcome the negative effects of stall by using casing treatment.

Kurokawa et al. [1] were the first who stabilized the performance curve of a mixed flow pump without decreasing the maximum of the pump efficiency. They formed shallow grooves within the casing wall, parallel to the pressure gradient.

Goltz [2] adapted this method successfully for a singlestage axial-flow pump. But she mentioned as well a disadvantage, the occurrence of strong cavitation at the inlet of the grooves for flow rates below the stall point.

This cavitation could not be extracted from the $\mathrm{NPSH}_{3}-$ values but can lead to a destruction of the grooved casing. A continuous operation for flow rates below the stall point is hence not possible.

Therefore, another method to stabilize the performance curve will be presented in this paper.

\section{PREVIOUS WORK}

Goltz et al. [2-6] showed the flow structures of a single-stage axial-flow pump from stable operation until deep stall. After the onset of stall, a short transient takes place. During the transient Goltz observed spiral-type vortex-breakdown (see Figure 2). The kinking of the vortex lead to an enormous blockage so that the inlet flow is forced to separate from the casing, and hence the backflow could suddenly expand upstream of the rotor. The expansion of the back flow is not only increased in axial direction but also in radial direction. The backflow has a large circumferential component which is transmitted to the inlet flow and as a consequence the outer $30 \%$ to $40 \%$ span is affected by strong preswirl, which is the cause for the sudden drop of head.

The grooves used by Goltz [2] in an axial flow pump, see Figure 1 and the grooves used by Kurokawa et al. [1] in a mixed flow pump are both able to absorb the strong angular momentum of the back flow. When reaching the grooves, the backflow is forced to change the direction and loses swirl due to friction and forming vortices. Hence the inlet flow is less affected by the back flow.

Figure 3 shows the axial and circumferential components of the time mean absolute velocities in front of the rotor at deep stall measured by Goltz [2]. The casing wall is on 


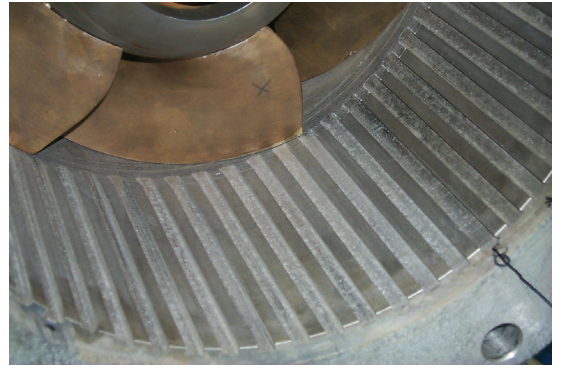

FIgURE 1: Flat axial grooves in front of the rotor used by Goltz [6].

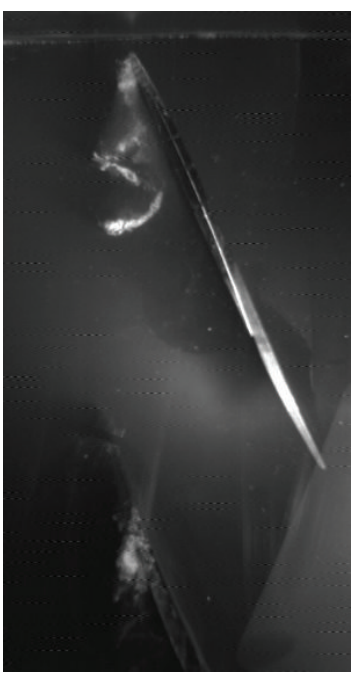

(a)

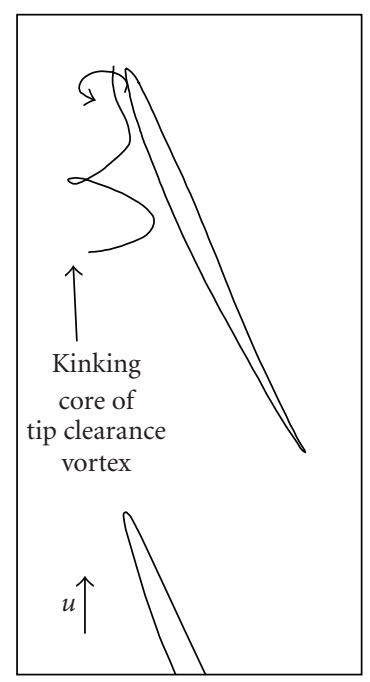

(b)
FIGURE 2: Vortex breakdown of the tip clearance vortex observed by Goltz [4].

a radius $r=170 \mathrm{~mm}$, the hub on a radius $r=60 \mathrm{~mm}$. It can be seen that the radial extension of the backflow has increased to approximately $20 \%$ of blade span. These results are confirmed by numerical investigations, see Benra et al. [7]. By using the grooved casing the circumferential component is well reduced.

\section{EXPERIMENTAL SETUP}

\subsection{Test rig and test pump}

The test pump is a scaled-down model of the axial-flow pump used by Goltz $[2,3]$ with a specific speed of $n_{q}=150$ and a casing diameter of $D=150 \mathrm{~mm}$.

This pump was also already used by Goltz [4]. However, unlike the former horizontal installed pump, the pump is now installed vertically and takes in water from an open intake chamber (Figure 4). Another difference is that the pump casing has no spherical part but is entirely cylindric. The chamber is made of plexiglass in order to observe the flow and to conduct measurements with particle image velocimetry (PIV). Figure 5 shows the head characteristics of the vertically installed pump in comparison with the test pump used by Goltz.

\subsection{Double-inlet-nozzle}

Since the grooves have the disadvantage of strong cavitation at the grooves inlet area as mentioned above another method for stabilizing was conceived. Based on the knowledge of the flow structures, the idea is to discharge the backflow with its high swirl. Hence the mixing of backflow and inlet flow and the transfer of angular momentum is prevented. Therefore, a so called double-inlet-nozzle was built (see Figure 6). Between the two nozzles, there is a gap which serves as an additional inlet during stable operation and serves as discharge for the extended backflow when operating in the stall regime.

All measurements at this test rig were performed at a rotational speed of $n=1150 \mathrm{l} / \mathrm{min}$.

\subsection{Test procedure}

In order to show the flow field at the inlet of the doubleinlet-nozzle, a Dantec PIV-System was used (type New Wave Gemini Nd:YAG PIV-laser).

For these measurements, the Planar-PIV-method was applied, camera and laser were installed perpendicular to each other (Figure 7). The water was seeded with polyamide particles with an average diameter of $20 \mu \mathrm{m}$. The pulsed laser exposed 2 images which are recorded by a 12-bit CCDcamera with $1024 \times 1280$ pixels. For post processing, an adaptive cross correlation was used followed by a statistical analysis of 14 single correlations and finally a moving average validation has been applied.

The laser produces a light sheet below the inlet nozzle. The measuring plane is located in the machine axis. It is divided into 6 single measuring windows. Each window has the length $x=84 \mathrm{~mm}$ and $y=106.5 \mathrm{~mm}$. They overlap each by $4 \mathrm{~mm}$.

An additional window is situated at the gap between the two nozzles. Its dimension is $68.8 \times 109.2 \mathrm{~mm}$. Because of the holder from the double-inlet-nozzle, that hinders the light sheet, the measuring plane for this window is chosen $20 \mathrm{~mm}$ outside of the machine axis (Figure 7).

The flow field was also measured at the inlet of the original smooth casing. Because the outer diameter of the inlet-nozzle here is smaller than with the double-inletnozzle, only 5 measuring windows $(84 \times 106 \mathrm{~mm})$ form the measuring plane.

For investigating the prerotation at 4 axial chord-lengths upstream of the rotor a tilted mirror was used (Figure 11). The laser is located at the opposite site of the plexiglass box. The post processing used was the same as before. All PIV-measurements have been carried out by Hauschke [9].

Besides the PIV-measurement also the head performance and the efficiency of the pump were recorded. The efficiency was measured by a torque measuring shaft. 


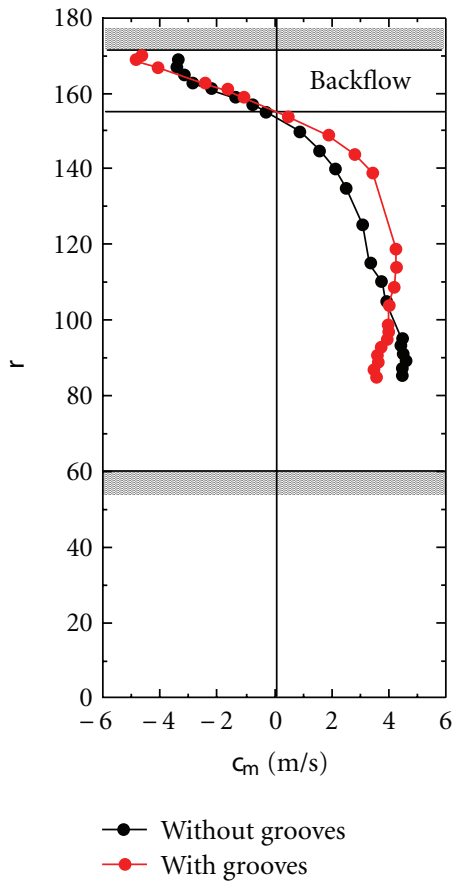

(a)

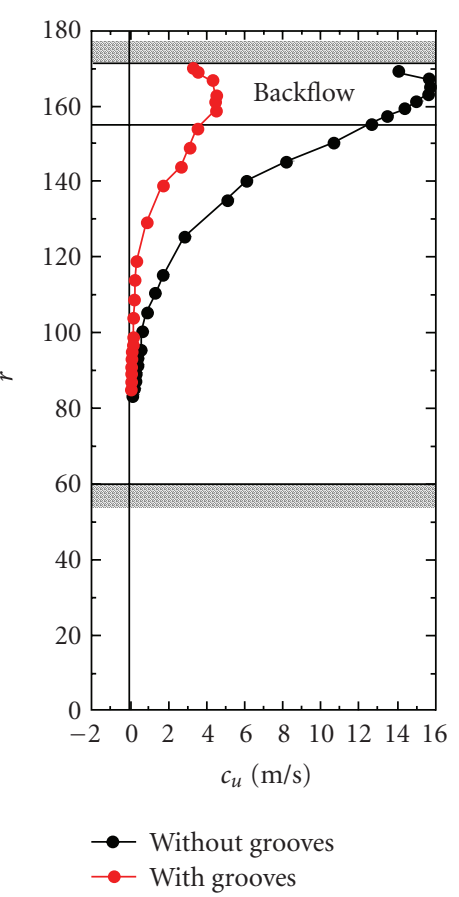

(b)

FIGURE 3: Axial and circumferential components of the time mean absolute velocities in front of the rotor in deep stall, $Q / Q_{N}=0.48$, $\mathrm{NPSH}_{A}=35 \mathrm{~m}$, Kosyna et al. [8].

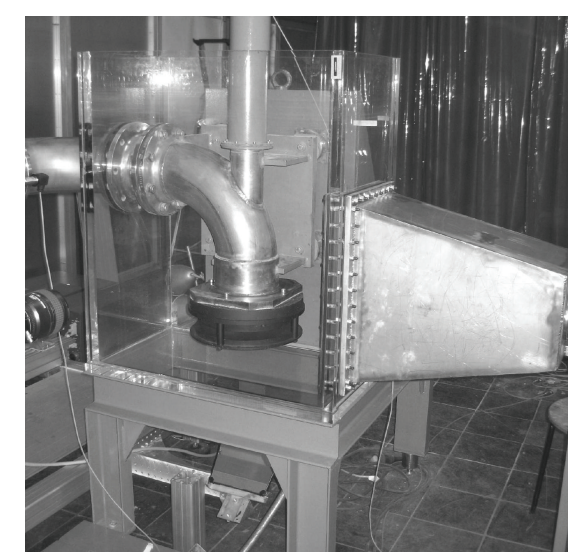

FIGURE 4: Intake chamber and pump with double inlet nozzle.

\section{RESULTS AND DISCUSSION}

\subsection{Pump head characteristic and efficiency}

Figure 8 shows the pump head characteristics and the pump efficiencies of the original casing, the casing with grooves and the double-inlet-nozzle.

The head characteristic shows that the last point of the stable branch of the original casing is located at approximately $Q / Q_{\text {opt }}=0.7$. Reducing the mass flow even further will lead to the drop in pump head. But using the casing with

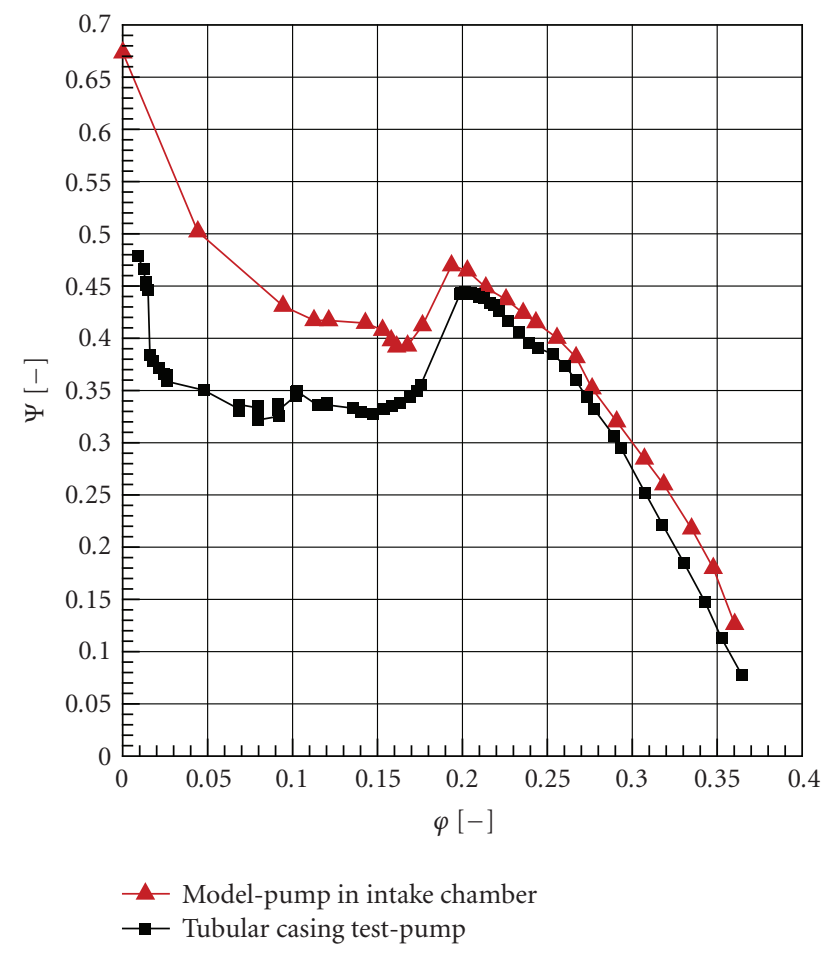

FIgURE 5: Head characteristic without casing treatment of model-pump (DN 150) installed vertically in intake chamber and horizontal tubular casing test-pump (DN 350) used by Goltz. 


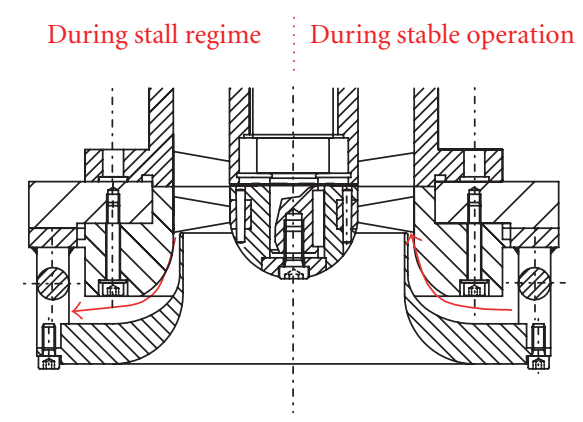

FIGURE 6: Design drawing of double-inlet-nozzle.

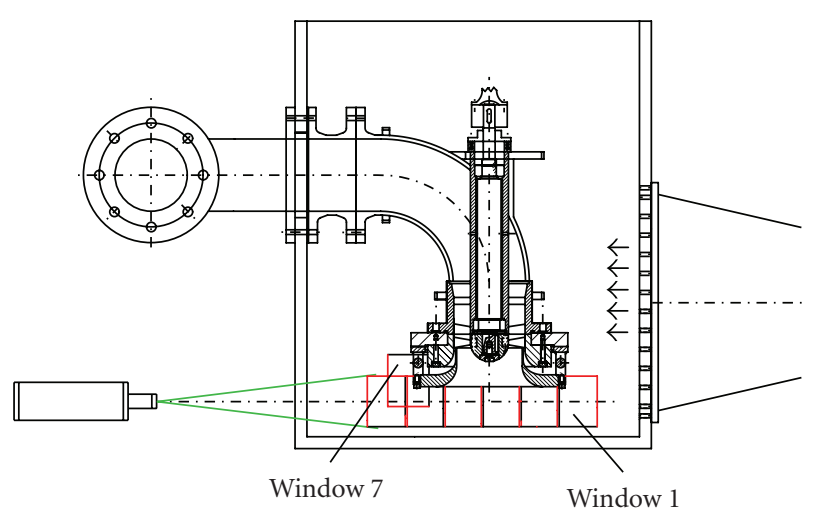

(a)

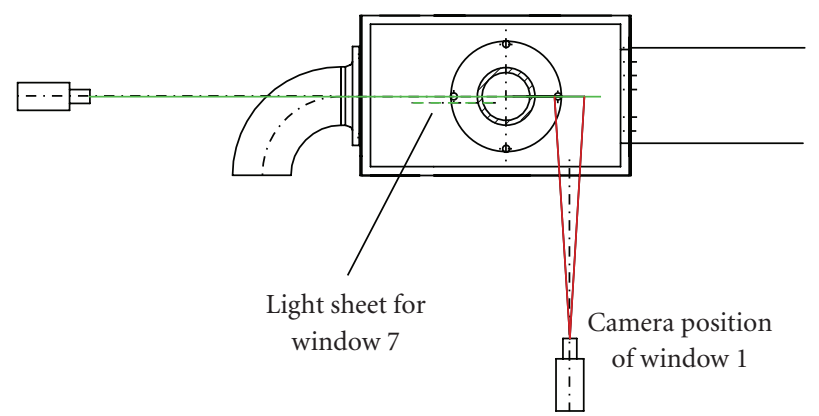

(b)

FIGURE 7: Position of the measuring windows for the examination of the inlet flow of the double-inlet-nozzle (above) and sketch from below (below).

grooves or the double-inlet-nozzle the head characteristics show a small saddle and than the pump head grows again.

The efficiency of all the three casings remains the same until the onset of stall. From there, the efficiency with the grooved casing and with the double-inlet-nozzle is higher. It is remarkable that for the latter the blockage due to the additional nozzle has negative influences neither on the head performance nor on the efficiency.

\subsection{PIV-measurement of the inlet flow near design}

Figure 9 shows the inlet flow near design conditions for the double-inlet-nozzle and for the original smooth casing. The size of the vectors and also the colors illustrate the absolute

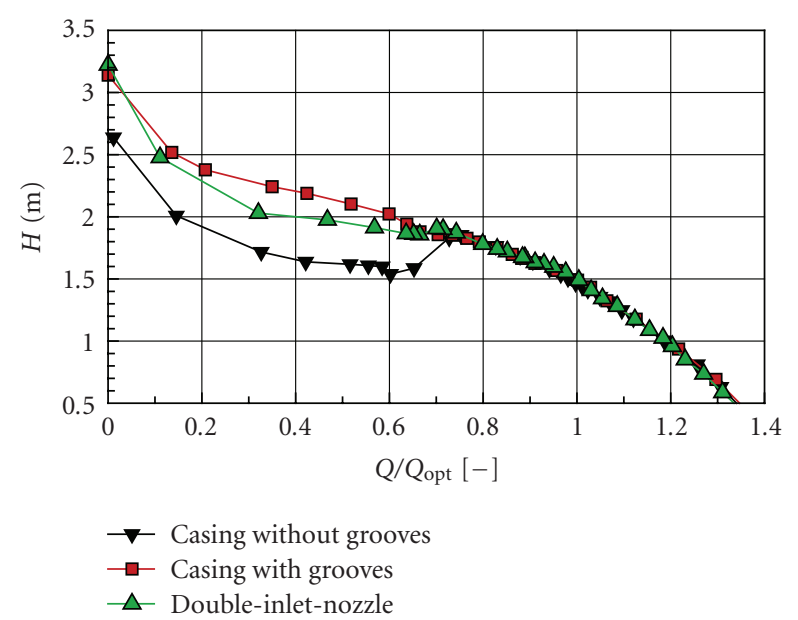

(a)

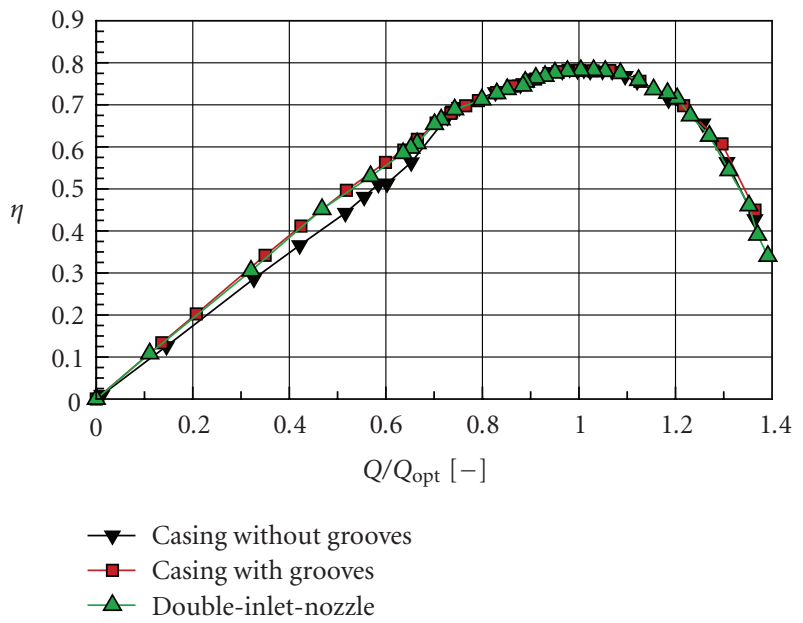

(b)

Figure 8: Pump head (above) and pump efficiency (below) of original smooth casing, grooved casing and double-inlet-nozzle.

velocity $c$ composed of the two velocity-components $c_{\mathrm{ax}}$ and $c_{r}$ in the image plane. The pictures are each composed of 7 and 5 windows, respectively, which represent again an average of 14 individual measurements. For a better overview, only every 4 vector in the $x$ - and $y$-direction is shown. For the window at the gap only every 6 vector is shown.

The flow approaches the pump from the right side.

For the double-inlet-nozzle, the inlet flow is nearly symmetrically to the machine axis. For the smooth casing without grooves this does not apply well. One reason could be that the outer diameter of the inlet-nozzle of the smooth casing is smaller than the outer diameter of the double-inletnozzle and that because of this the flow under the doubleinlet-nozzle has more space to get uniform.

Besides the symmetry there can hardly be found any differences between the inlet flows of both casings.

In the upper figure, the small inlet flow into the gap between both nozzles can be seen. About 13\% of the mass flow enters the pump through the gap. 


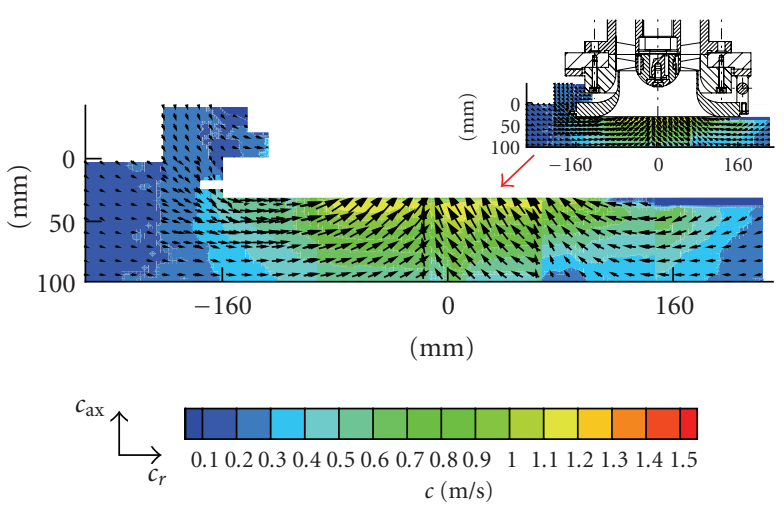

(a)

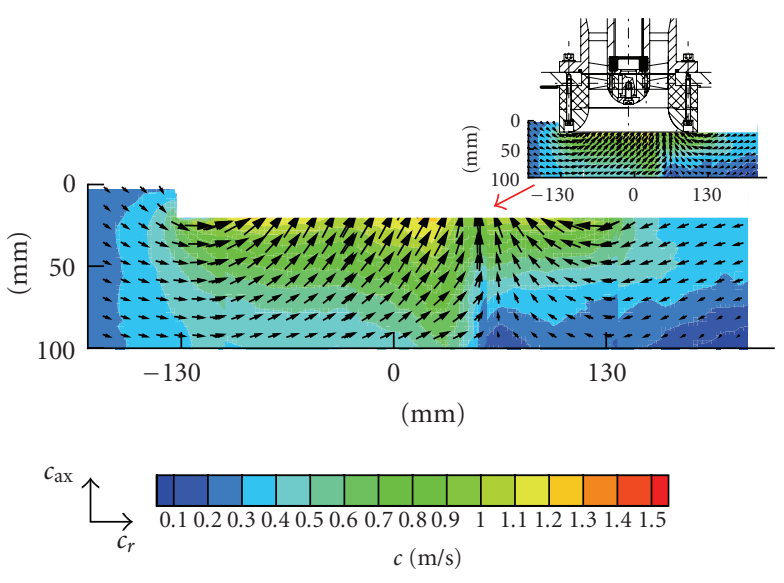

(b)

FIgURE 9: Inlet flow of the double-inlet-nozzle (a) and of the original casing (b) near design conditions, $\mathrm{Q} / \mathrm{Q}_{\mathrm{opt}}=1.06, c=$ $\left(c_{\mathrm{ax}}^{2}+c_{r}^{2}\right)^{1 / 2}$.

\subsection{PIV-measurement of the inlet and outlet flow at deep stall}

Figure 10 shows the inlet flow at deep stall conditions. The discharged near wall backflow of the original casing without grooves (Figure 10(b)) is deflected by the approaching flow and reenters into the inlet nozzle. This causes a vortex over the whole circumference, so that the vortex has the shape of a torus. At Figure 10(b) the cross section view of the vortex in the machine axis can be seen. The core of the vortex shows a blockage which can be seen in the middle.

However the inlet flow at the double-inlet-nozzle (Figure 10(a)) is still smooth. The discharged flow is ejected off the gap. According the principle of angular momentum, the circumferential velocity component will be reduced on the way outwards. At a radius $r=127 \mathrm{~mm}$ the maximum velocity of $c_{r}$ is about $20 \%$ of the circumferential velocity $u_{2}$.

\subsection{PIV-measurement of the prerotation in deep stall}

Figures 12 and 13 show a comparison of the prerotation at 4 times the length of span $L$ upstream of the rotor. In order to know the position of the impeller, the border of the rotor
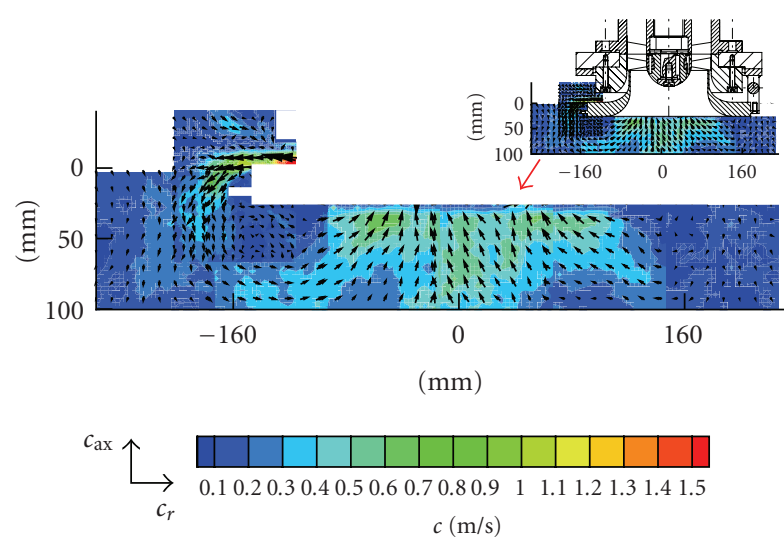

(a)

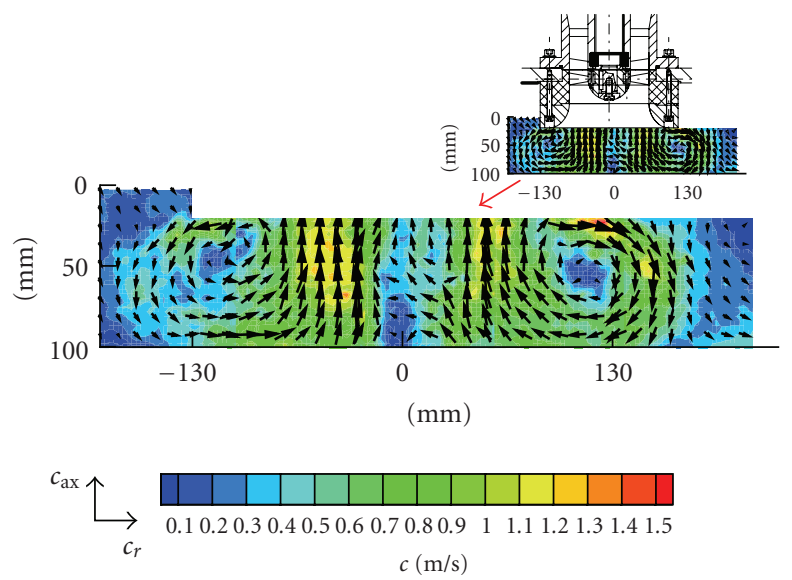

(b)

Figure 10: Inlet flow of the double-inlet-nozzle (a) and of the original casing (b) at stall conditions and discharge of the backflow at the gap in (a), $Q / Q_{\text {opt }}=0.3, c=\left(c_{\mathrm{ax}}^{2}+c_{r}^{2}\right)^{1 / 2}$.

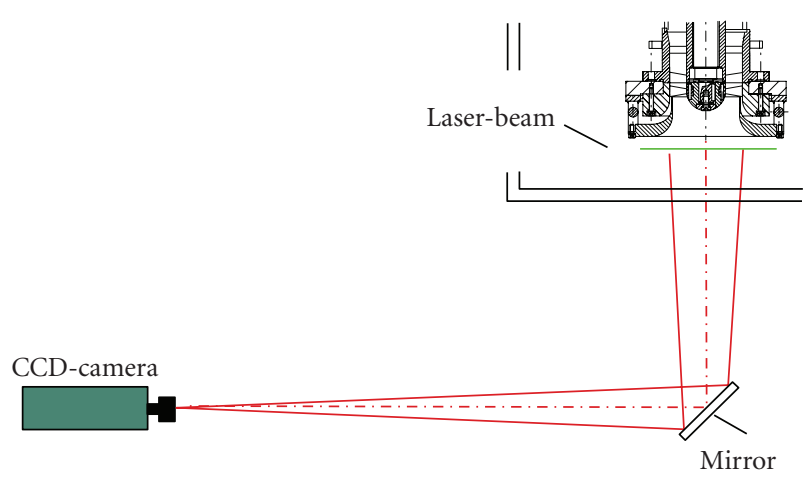

FIgURE 11: Optical path for investigation of the prerotation.

is shown. The size of the vectors and also the colors show the composed velocity of the two velocity-components in the image plane. The occurrence of prerotation is found at both casings. But with the double-inlet-nozzle the maximum velocity $c_{u}$ is approximately $20 \%$ lower than with the original casing. 


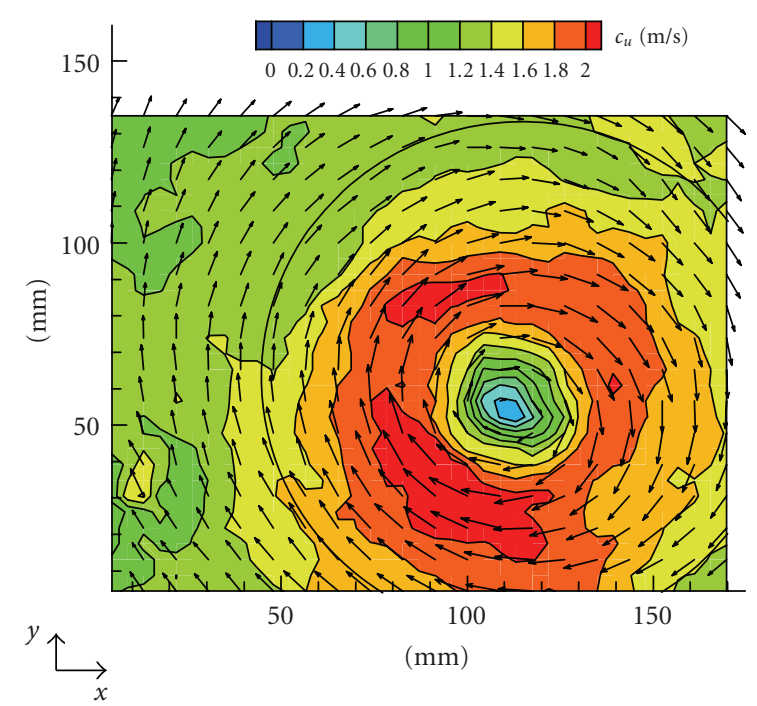

Figure 12: Prerotation at original casing at stall conditions, $\mathrm{Q} / \mathrm{Q}_{\mathrm{opt}}=0.3,4 L$ upstream of the rotor. $c_{u}=\left(u^{2}+v^{2}\right)^{1 / 2}$.

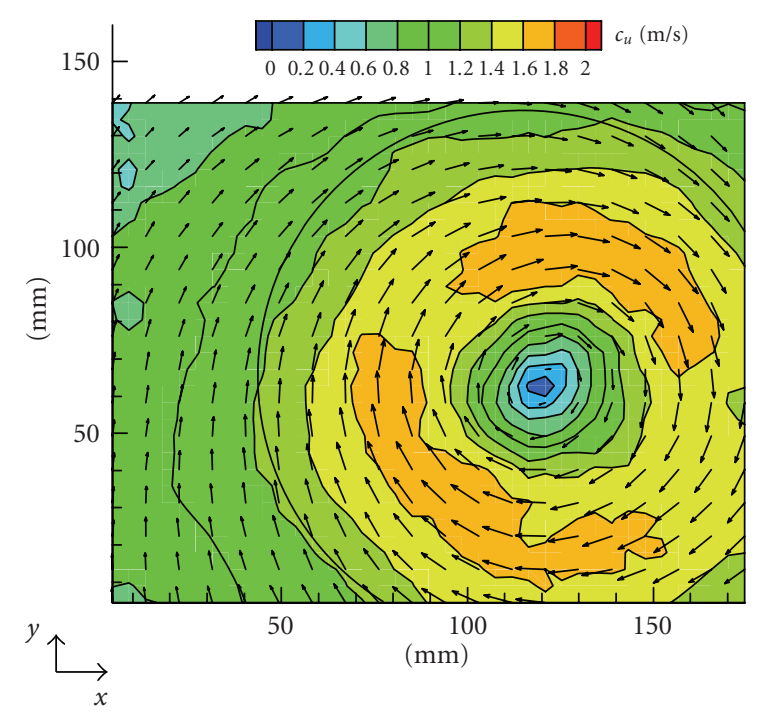

FIgURE 13: Prerotation at double-inlet-nozzle at stall conditions, $\mathrm{Q} / \mathrm{Q}_{\mathrm{opt}}=0.3,4 L$ upstream of the rotor. $c_{u}=\left(u^{2}+v^{2}\right)^{1 / 2}$.

\section{CONCLUSION AND FUTURE WORK}

This investigation showed that the double-inlet-nozzle, developed at Pfleiderer-Institut,

(i) reduces the preswirl upstream of the impeller by discharging the backflow when operating in stall regime,

(ii) stabilizes the head performance of an axial-flow pump as well as a grooved casing without suffering from cavitation at the grooves,

(iii) reduces the prerotation upstream of the rotor in deep part load conditions, and

(iv) does not reduce the efficiency although the cross section is partly blocked by the second inlet nozzle.
Further investigations are as follows:

(i) variation of the axial position of the second nozzle,

(ii) NPSH-measurements by using a closed intake chamber with variable system pressure,

(iii) measurements of vibrations, shaft stresses, and sound level,

(iv) numerical investigation.

\section{NOMENCLATURE}

$c[\mathrm{~m} / \mathrm{s}]: \quad$ Absolute velocity

$d[\mathrm{~mm}]: \quad$ Impeller diameter

$d_{n}[\mathrm{~mm}]: \quad$ Hub diameter

$D[\mathrm{~mm}]: \quad$ Casing diameter

$H[\mathrm{~m}]: \quad$ Pump head

$L[\mathrm{~mm}]: \quad$ Axial chord length

$n\left[\mathrm{~min}^{-1}\right]: \quad$ Rotational speed

$n_{q}[-]: \quad$ Specific speed

$$
n_{q}=333 \cdot n\left[\mathrm{~s}^{-1}\right] \cdot \sqrt{\mathrm{Q}\left[\mathrm{m}^{3} / \mathrm{s}\right]} /(H[\mathrm{~m}] \cdot g)^{3 / 4}
$$

$\mathrm{NPSH}_{3}[\mathrm{~m}]: \mathrm{NPSH}_{A}$ at $3 \%$ head loss

$Q\left[\mathrm{~m}^{3} / \mathrm{h}\right]$ : Volume flow rate

$r[\mathrm{~mm}]: \quad$ Radius

$u_{2}[\mathrm{~m} / \mathrm{s}]: \quad$ Circumferential velocity at the outer impeller

$u[\mathrm{~m} / \mathrm{s}]: \quad$ Velocity component in $x$-direction

$v[\mathrm{~m} / \mathrm{s}]: \quad$ Velocity component in $y$-direction

$\varphi[-]: \quad$ Flow coefficient

$\varphi=(4 \cdot Q) /\left(\pi \cdot u_{2} \cdot\left(d^{2}-d_{n}^{2}\right)\right)$

$\psi[-]: \quad \quad$ Pressure coefficient $\psi=(2 \cdot g \cdot H) / u_{2}$

\section{Subscripts}

ax: Axial

$r$ : Radial

\section{ACKNOWLEDGMENTS}

The authors thank Deutsche Forschungsgesellschaft (DFG) for supporting the investigation. This paper was presented at The 12th International Symposium on Transport Phenomena and Dynamics of Rotating Machinery, Honolulu, Hawaii, February 17-22, 2008.

\section{REFERENCES}

[1] J. Kurokawa, S. L. Saha, J. Matsui, and H. Imamura, "An innovative device to suppress performance-curve-instability in a mixed-flow pump by use of J-grooves," in Proceedings of the 3rd ASME/JSME Joint Fluids Engineering Conference (FEDSM '99), San Francisco, Calif, USA, July 1999, FEDSM99-7200.

[2] I. Goltz, Entstehung und Unterdrückung der Kennlinieninstabilität einer Axialpumpe, Pfleiderer-Instituts für Strömungsmaschinen, Heft 10, Faragallah, Sulzbach, Germany, 2006, Dissertation TU Braunschweig.

[3] I. Goltz, G. Kosyna, U. Stark, H. Saathoff, and S. Bross, "Stall inception phenomena in a single-stage axial-flow pump," Proceedings of the I MECH E Part A Journal of Power and Energy, vol. 217, no. 4, pp. 471-479, 2003. 
[4] I. Goltz, G. Kosyna, D. Wulff, H. Schrapp, and S. Bross, "Part load operating performance and stall inception of a singlestage axial-flow pump," in Proceedings of the 10th International Symposium on Transport Phenomena and Dynamics of Rotating Machinery (ISROMAC '04), Honolulu, Hawaii, USA, March 2004.

[5] I. Goltz, G. Kosyna, D. Wulff, et al., "Structure of the rotor tip flow in a highly-loaded single-stage axial-flow pump approaching stall part II: stall inception-understanding the mechanism and overcoming its negative impacts," in Proceedings of the ASME Heat Transfer/Fluids Engineering Summer Conference (HT/FED '04), pp. 301-306, Charlotte, NC, USA, July 2004, HT-FED2004-56770.

[6] I. Goltz, G. Kosyna, D. Wulff, U. Stark, H. Saathoff, and S. Bross, "Performance instability of an axial-flow pump: origin and prevention," in Proceedings of the International Pumps User Forum, pp. 607-618, Karlsruhe, Germany, September 2004.

[7] F.-K. Benra, H. J. Dohmen, and M. Schmidt, "Flow phenomena in a highly-loaded single-stage axial-flow pump-comparison of experimental and numerical results," in Proceedings of the 5th Joint ASME/JSME Fluids Engineering Summer Conference (FEDSM '07), pp. 979-984, San Diego, Calif, USA, July-August 2007, FEDSM2007-37552.

[8] G. Kosyna, I. Goltz, and U. Stark, "Flow structure of an axialflow pump from stable operation to deep stall," in Proceedings of ASME Fluids Engineering Division Summer Conference (FEDSM '05), pp. 1389-1396, Houston, Tex, USA, June 2005, FEDSM2005-77350.

[9] A. Hauschke, "Untersuchung der Einlaufströmung einer Axialpumpe bei verschiedenen Einlaufgeometrien mit Hilfe von particle Image Velocimetry," Studienarbeit am PfleidererInstitut für Strömungsmaschinen, 2007. 

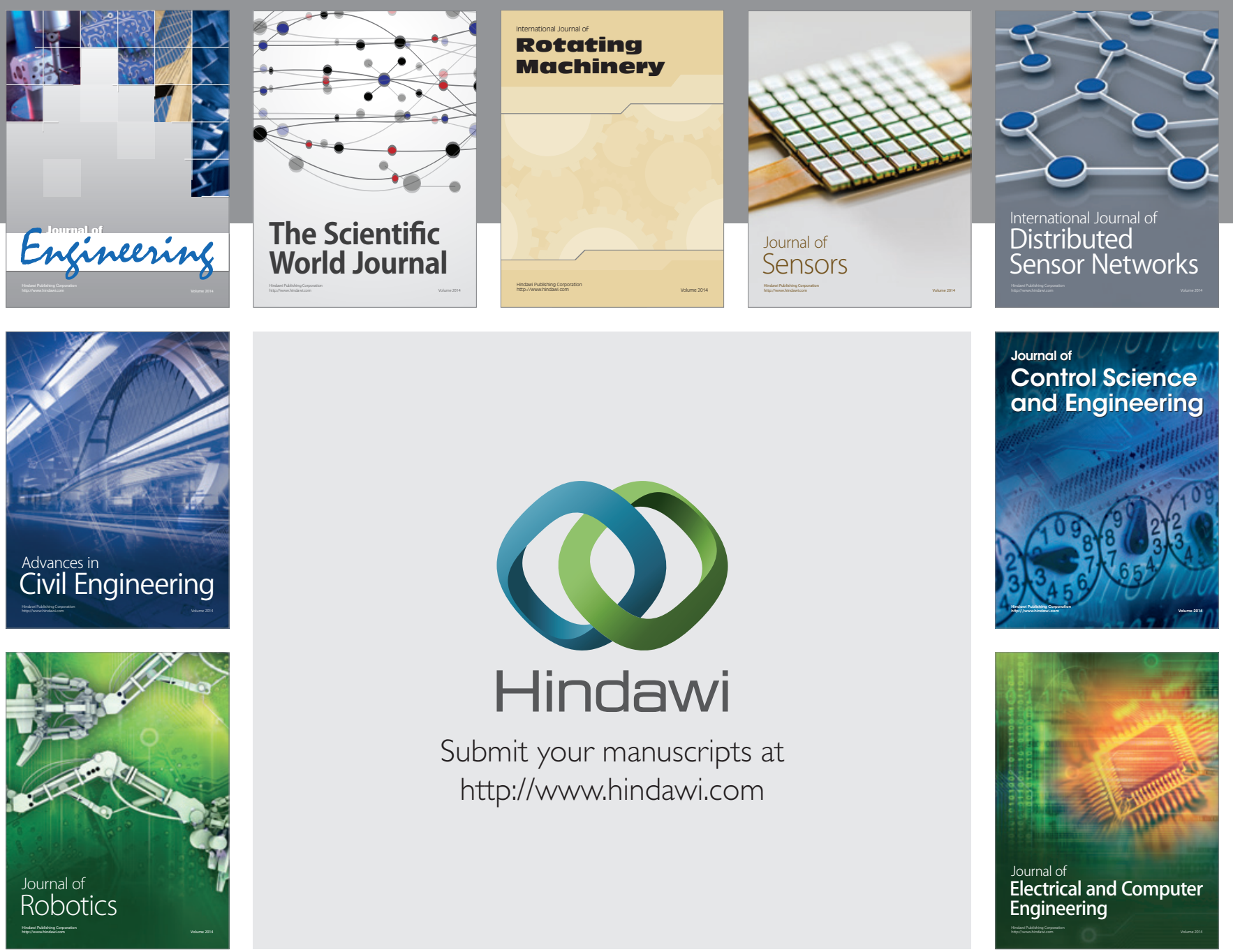

Submit your manuscripts at

http://www.hindawi.com
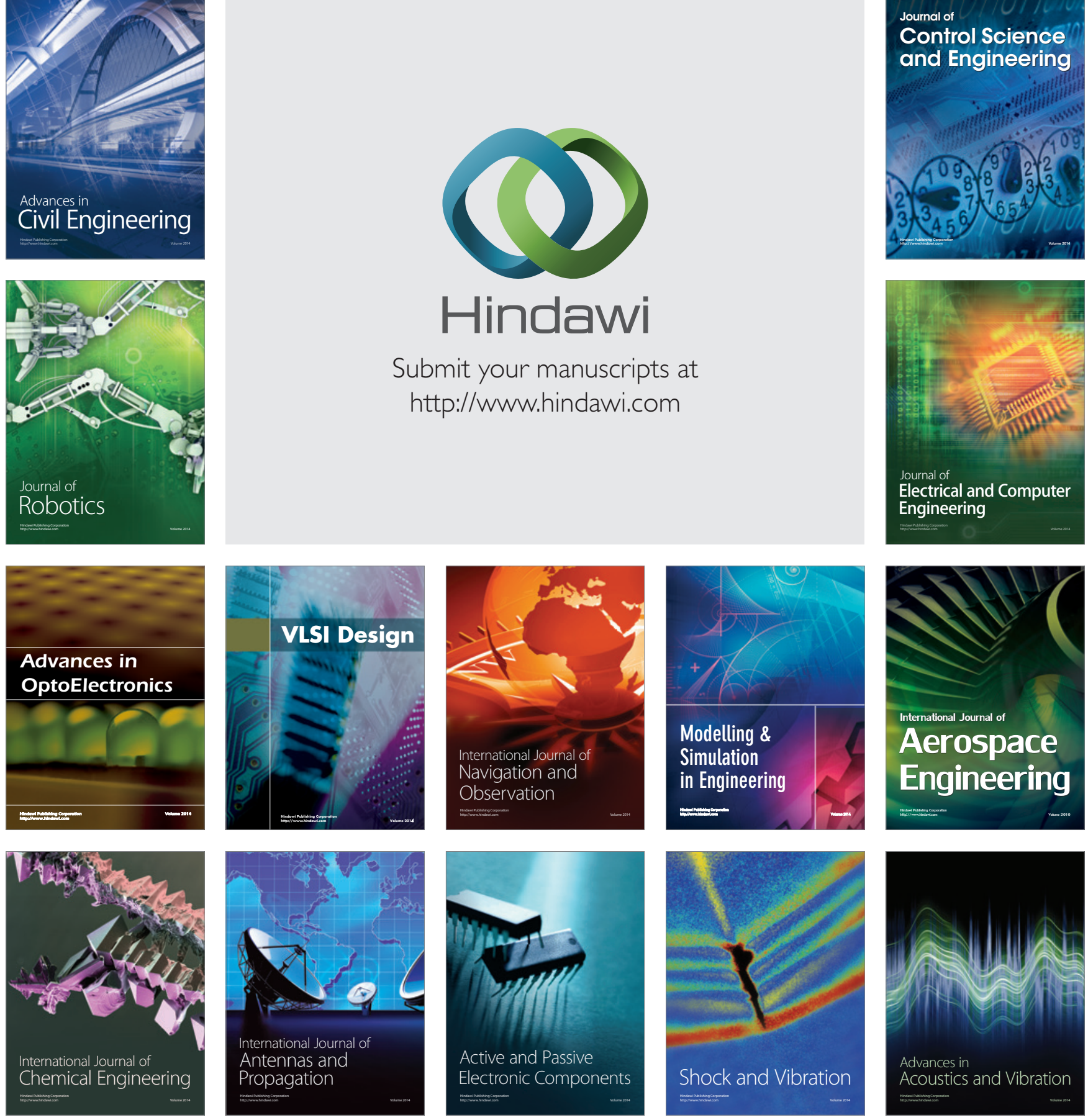